\title{
The Correlation of Values of Cd4 Count, Platelet, Pt, Aptt, Fibrinogen and Factor VIII Concentrations among HIV Positive Patients in FMC Owerri
}

\author{
Okoroiwu Ijeoma Leticia ${ }^{1}$, Amadi Ugochukwu ${ }^{2}$, Obeagu Emmanuel Ifeanyi ${ }^{3}$, \\ Anode Andrew ${ }^{4}$ and Udokwu Euphemia Ifeoma ${ }^{4}$ \\ 1. Lecturer (P.hD), Department of Medical Laboratory Science, Faculty of Health Science, Imo State \\ University, Owerri, Nigeria. \\ 2. Department of Medical Laboratory Science, Federal Medical Centre, Owerri, Imo State, Nigeria. \\ 3. Diagnostic Laboratory Unit, University Health services Department, Michael Okpara University of \\ Agriculture, Umudike, Nigeria. \\ 4. Department of Medical Laboratory Science, Federal Medical Centre, Umuahia, Abia State, Nigeria.
}

\begin{abstract}
The correlation of values of CD4 Count, platelet, PT, APTT, fibrinogen and factor viii was carried out. One hundred and sixty four subjects were sampled, comprising one hundred and fourteen HIV positive subjects and fifty HIV negative subjects which served as the control. PT, APTT, Fibrinogen, Factor VIII, Platelet and CD4 count were analyzed using standard techniques. The results showed that HIV positive subjects

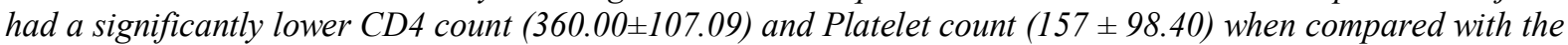
$H I V$ negative subjects $(940 \pm 220.05)$ and $(228 \pm 62.04)$ respectively. Also PT and APTT were significantly higher $(P<0.05)$ in HIV positive subjects $(19.56 \pm 3.14)$ and $(42.86 \pm 7.10)$ respectively when compared with the $H I V$ negative subjects $(14.90 \pm 1.91)$ and $(37.90 \pm 3.98)$ respectively. Whereas, there were no significant changes $(P>0.05)$ in fibrinogen and factor viii concentration between the HIV Positive subjects and the HIV negative subjects. Among the HIV positive subjects, platelet count did not differ significantly $(p>0.05)$ between those with CD4 count $<200$ cells/ $\mu$ l and those with CD4 count $\geq 200 \mathrm{cells} / \mu \mathrm{l}$. However, PT and APTT showed significant changes $(22.40 \pm 2.96)$ and $(48.20 \pm 8.01)$ respectively, in HIV Positive subjects with CD4 count $<200 \mathrm{cells} / \mu \mathrm{l}$. Furthermore, there were positive correlation between PT and APTT, PT and CD4 count, APTT and CD4 count, Platelet and CD4 count $(P<0.01)$ respectively while there were no correlation between other coagulation parameters tested $(P>0.01)$.
\end{abstract}

Keywords: CD4 Count, PT, APTT, fibrinogen and factor viii.

\section{Introduction}

Human Immunodeficiency Virus (HIV) is a lentivirus (a member of the retrovirus family) that causes acquired Immunodeficiency Syndrome (AIDS) (Weiss, 1993). This is a condition in humans in which progressive failure of the immune system allows life threatening opportunistic infection and cancers to thrive. Infection with HIV occurs by the transfer of blood, semen, vaginal fluid, pre-ejaculate or breast milk of the infected person to HIV free person. Within these body fluids, HIV is present as both free virus particles and virus within infected immune cells. The four major routes of transmission are unsafe sex, contaminated needles, breast milk, and transmission from an infected mother to her baby at birth (perinatal transmission) (Fox et al., 1992).

Viruses such as HIV cannot grow or reproduce on their own, the need to infect the cells of a living organism in order to replicate. The human immune system usually detects and kills viruses fairly quickly, but HIV attacks the immune system itself, the very thing that would normally get rid of the virus. (Ascher et al., 1990)

HIV is a causative organism of autoimmune deficiency syndrome which was recognized as a new disease syndrome in the early 1980's in the USA with the unusual occurrence of pnemocystis carinii pneumonia and Kaposi's sarcoma in previously healthy young men (Greene, 1991). This retrovirus was isolated from a young homosexual man with lymphadenopathy. The virus was identified and classified in the family Retroviridae genus lentviranae (Baker et al., 2007).

Under the electron microscope, the viruses were revealed as a cylindrical core with nucleic acid cloned and sequenced. The cylindrical core is $80-130 \mathrm{~nm}$ in diameter, it has a unique three layered structure, and innermost is the genome nucleocapside complex. This complex is enclosed within a capsid which is surrounded by a host cell membrane derived envelope, from which viral envelope glycoprotein 'spikes' project. HIV infects a wide variety of tissues in humans including the marrow, lymph node, brain, skin and bowel (Baker et al., 
2007). This retrovirus differs from other retroviruses such as human T lymphotrophic virus (HTLV) 1 and 2. The virus was eventually named Human Immunodeficiency Virus (Cohan et al., 1986).

It is transmitted mostly sexually in blood or blood products and pre-natally. The most at risk of acquiring HIV infection are homosexuals, injecting drug misusers and those with bisexual orientation. Others include individuals receiving unscreened blood or blood products, infants born of infected women.

There are various strains of HIV and are designated by a code with geographically informative letters and sequential numbers placed either in brackets, or as a number, or as a subscript. Example HIV 1and HIV 2 (Pantaleo et al., 1995)

If there is a laboratory evidence of HIV infection, certain indicator diseases that require presumptive and definitive diagnosis are diagnostic of AIDS, AIDS is an illness characterized by one or more indicator diseases. (Safrit et al., 1995).

Acute HIV is usually characterized by fever, malaise, lymphadenopathy and rash. These conditions are subclinical. A chronic infection of AIDS that follows is asymptomatic in early stages. If an individual is infected with this virus, the virus acts so quick destroying the immune system making the individual prone to little infections. HIV is present all over the world and the long term consequences of this pandemic will affect every country one way or another over time. This is an evolving pandemic threatening global public health and health care provision, as well as political and economic stability.

(Kuby Janis, 1997).

Coagulation results from interactions among vessel wall, platelet and coagulation factors. When an injury occurs that results in bleeding, the coagulation system is activated and plugs the hole in the bleeding vessel while still keeping blood flowing through the vessels by preventing the clot from getting too large. The end result is the formation of insoluble fibrin threads that link together at the site of injury, along with aggregated cell fragments called platelets to form a stable blood clot. The clot prevents additional blood loss and remains in place until the injured areas have healed. The clot is eventually removed as the injured site is healed. In normal healthy individuals, this balance between clot formation and removal ensures that bleeding does not become excessive and that clots are removed once they are no longer needed. (Shapiro, 2003).

A number of coagulation abnormalities have been described in human immunodeficiency virus (HIV) disease. High levels of plasma von Willebrand factor have been reported in HIV disease and might be indicative of activated endothelium. Endothelium is involved in important homeostatic mechanisms of non-thrombotic vascular surfaces, vascular tone regulation and immunomodulation (Karpatkin et al., 2002). Injured endothelium leads to localized inflammatory response of which the direct consequence is the occurrence of occlusive thrombosis events mediated between leucocyte recruitment and platelet adhesion and aggregation, blood clothing activation and fibrinolysis derangement. HIV infection has been associated with endothelial dysfunction. Since HIV infection is associated with endothelial dysfunction it may therefore result in activation and consumption of coagulation factors and ultimately coagulation defect. (Omoregie et al., 2009).

In HIV infection, the liver is affected. The liver is the major organ responsible for the synthesis of most coagulation factors and infection of the liver by HIV can lead to abnormal production of coagulation factors. The $\mathrm{CD}^{+}$count is used to measure immune status and HIV disease progression (Tolstrup et al., 2004).

Prothrombin time (PT) an activated partial thromboplastin time (APTT) are screening tests for the extrinsic and intrinsic clothing systems respectively. They detect deficiency or inhibition of clotting factors in either system, and are the first tests in screening for coagulation disorders. As HIV infection progresses, endothlieal dysfunction and liver damage will increase and this may result in severe clotting impairment.

In reference to the abnormality of coagulation in HIV positive individuals, the coagulation disorders will be investigated, by considering platelet count, prothrombin time, activated partial thromboplastin time, and blood fibrinogen concentration, as well as $\mathrm{CD}_{4}$ count and factor VII concentration.

Platelet count is a diagnostic test that determines the number of platelets in the patient's blood. Platelet which are also called thrombocytes, are small disk-shaped blood cells produced in the bone marrow and involved in the process of blood clotting. There are normally between 150,000-450,000 platelets in each microlitre of blood. Low platelet count or abnormally shaped platelets are associated with bleeding disorders .

Prothrombin time (PT), is one of the coagulation factors produced by the liver. One of the final steps of the cascade is the conversion of Prothrombin (factor 11) to thrombin. The Prothrombin time test evaluates the integrated function of the coagulation factors that comprises the extrinsic and common pathways.

The international Normalized Ratio (INR) is used to standardize PT result gotten (Horsti et al., 2005).

Activated partial thromboplastin time (APTT), is a screening test that is done to help evaluate a person's ability to form blood clot. It assesses the amount as well as the function of coagulation factors XII, IX, VII, X, V, II and I which are part of haemostasis (Pagana \& Pagana, 2006).

Fibrinogen (factor 1) is a soluble plasma glycoprotein synthesized by the liver and is converted by thrombin into fibrin during blood coagulation. 
Fibrinogen deficiency (hypo-fibrinogenemia) or disturbed function of fibrinogen can lead to either bleeding or thromboembolic complications (Acharga \& Dimichele, 2008).

$\mathrm{CD} 4$ count is the number of CD4 cells per microlitre of blood. It is used to stage the patient's disease, determine the risks of opportunistic illness, assess prognosis and guide decisions about when to start antiretroviral treatment (CDC, 2009).

\section{JUSTIFICATION}

A number of coagulation abnormalities have been associated with HIV disease. Endothelial cell injury is a common feature of viral infection and can alter haemostasis in a direct or indirect manner. It can be directly infected by different viruses such as HIV and CMV. Such infection may result in a procoagulant state, mainly by inducing tissue factor expression on the endothelial surface, probably mediated by cytokines such as IL-1, TNF and IL-6 (Llorente et al., 2004). An additional cause of enhanced coagulability may be prothrombinase complex assembly on the HIV surface. These observation suggests that the HIV surface contains the necessary procoagulant phospholipids for assembly of the coagulation enzyme complex leading to thrombin generation . Whereas, thrombocytopenia which can lead to the heamostasic impairment and bleeding complication is assumed to be immune mediated. The mechanism is decreased thrompoiesis, increased platelet consumption or a combination of both. Direct interaction of the virus with platelet may lead to thrombocytopenia, while endothelial cell injury by the virus may lead to increased adherence and consumption of platelet. High levels of plasma von Willebrand factor have been reported. In 2009, Omorege et al., (2009) reported an increase in APTT level in HIV positive individuals in Benin City, which were statistically significant. Therefore, it becomes imperative to obtain a baseline coagulation profile for HIV positive individuals in Owerri. Thus this study is meant to explore the clinical significance of platelet count, PT, APTT, fibrinogen and CD4 counts of HIV positive individuals attending Heart to Heart clinic of Federal Medical centre Owerri, Imo State.

\section{AIM}

To determine the correlation value of CD4 count, platelet count, PT, APTT, fibrinogen, factor viii and among HIV positive subjects in FMC Owerri.

\section{OBJECTIVES}

To determine the mean values of CD4 count and some coagulation parameters on HIV positive subjects.

To determine the values of some coagulation factors on different values of CD4 count.

To find the correlation of values of PT, APTT, Fibrinogen, Platelet, CD4 count and factor viii on HIV positive subjects.

\section{SAMPLE SIZE CALCULATION}

\section{Material And Methods}

Sample size was calculated using the formula proposed by Daniel, 1999. $\mathrm{n}=\frac{\mathrm{Z}^{2} \mathrm{P}(1-\mathrm{P})}{\mathrm{d}^{2}}$

Where $\mathrm{n}=$ sample size

$\mathrm{Z}=\mathrm{z}$ statistic for confidence level at $95 \%$ i.e. (1.96)

$\mathrm{P}=$ expected prevalence or proportion

$\mathrm{D}=$ degree of precision $(0.05)$

The sample size for this study was calculated based on Ifeoma et al., (2010) 8.1\% prevalence of HIV in Owerri in 2010 .

$$
\begin{aligned}
\mathrm{n} & =\frac{1.96^{2} \times 0.08(1.00-0.08)}{(0.05)^{2}} \\
& =114 \text { samples }
\end{aligned}
$$

\section{ETHICAL CLEARANCE}

The study was approved by the Federal Medical Centre Research and Ethics Committee and ethics clearance obtained before the study commenced.

\section{INFORMED CONSENT}

Participant information sheet (PIS) was given to the prospective participants. After reading and understanding the PIS, questions were asked and proper explanations given. They consented to participate in the study by signing the informed consent form.

\section{ELIGIBILITY CRITERIA}

Informed consented subjects (both HIV/AIDS positive patients and HIV negative controls).

SUBJECTS

One hundred and fourteen HIV positive subjects aged 18-65 years attending Heart to Heart clinic of Federal Medical Centre, Owerri between June and December, 2013 were screened. Fifty HIV negative subjects were also screened and they served as controls. 


\section{SAMPLE COLLECTION}

Informed consented subjects were sampled. About $7 \mathrm{mls}$ of blood was collected from all the subjects, $4.5 \mathrm{mls}$ of which was added into trisodium citrate container containing $0.5 \mathrm{mls}$ of trisodium citrate for coagulation studies (PT, APTT, Fibrinogen concentrate and factor viii assay). The sample was spun at 3000rpm for 10 minutes, and then the clear plasma was collected into a clean dry plastic container. The test was performed using Rayto semi auto coagulation analyzer, RT-2204C model manufactured by Rayto life and analytical sciences co. Ltd. The remaining $2.5 \mathrm{mls}$ was added into ethylene diamine tetra acetic acid (EDTA) bottle and mixed immediately by reverse uniform inversion for platelet and CD4 counts. Platelet count was performed using sysmex automated haematology analyzer KY21N model manufactured by sysmex corporation Kobe, Japan, while CD4 count was performed using cyflow counter 1 manufactured by paretic Gmbh, Germany.

\section{PROTHROMBIN TIME (PT) \\ (Quick one stage method, 1935) \\ PROCEDURE:}

The PT reagent was reconstituted by adding $5 \mathrm{mls}$ of its diluents mixed by inversion and allowed to stand at room temperature for 30 minutes. The reconstituted PT reagent was pre-warmed at $37^{0} \mathrm{C}$ for $10 \mathrm{mins}$. $50 \mu \mathrm{l}$ of the sample was added into the test cuvette and incubated for $2 \mathrm{mins}$ at $37^{\circ} \mathrm{C}$. Then $100 \mu 1$ of the prewarmed PT reagent was rapidly added and the time of clotting in second recorded.

\section{ACTIVATED PARTIAL THROMBOPLASTIN TIME (APTT) (Modified Kaolin Method) PROCEDURE:}

The APTT reagent was reconstituted with $4 \mathrm{mls}$ of distilled water, mixed by inversion and allowed to stand at room temperature for 30mins. $50 \mu \mathrm{l}$ of the sample was added into a test cuvette. Then $50 \mu \mathrm{l}$ of the reconstituted APTT reagent was added to the sample, the mixture was incubated for $3 \mathrm{mins}$ at $37^{0} \mathrm{C} .50 \mu \mathrm{l}$ of calcium chloride was rapidly added and the time of clotting in seconds was recorded.

\section{FIBRINOGEN ASSAY \\ (Clauss Method, 1957) \\ PROCEDURE:}

The sample is diluted with $450 \mu \mathrm{l}$ of imidazole buffer to $50 \mu \mathrm{l}$ of sample to give a 1:10 dilution. $200 \mu \mathrm{l}$ of pre-diluted sample is added to the test cuvette, the sample was incubated for $5 \mathrm{mins}$ at $37^{0} \mathrm{C}$. Then $100 \mu 1$ of bovine thrombin is added. The time of clot was recorded in seconds, while the concentration was recorded in $\mathrm{mg} / \mathrm{dl}$.

\section{PLATELET}

(Direct Current Detection Method)

By automation using Sysmex automated haematology analyzer KY21N model manufactured by Sysmex Corporation Kobe, Japan.

\section{PROCEDURE:}

The sample in EDTA bottle was places in the spiral mixer and allowed to mix very well. Whole blood mode was activated in the LCD screen, the sample number (code) was inputed via the key board and then the enter key. Then the sample was mixed very well again, the cap was removed and inserted into the probe, on that condition, the start switch was pressed. The LCD screen displays analyzing, the sample was removed and recapped. The unit executes automatic analysis and displays the result on the screen.

\section{CD4 COUNT}

By automation using cyflow counter 1 manufactured by Partec Gmbh Germany.

\section{PROCEDURE:}

Wash the machine twice with $960 \mu$ l cleansing solution, rinse with $960 \mu$ l of rinse solution. Run control using count check bead to get an acceptable peak. Then add $20 \mu \mathrm{l}$ of monoclonal antibody and $20 \mu \mathrm{l}$ of blood. Mix and incubate in the dark for $15 \mathrm{mins}$. Add $800 \mu \mathrm{l}$ of buffer and slot the tube in the machine. Results are displayed on the LCD screen.

FACTOR VIII ASSAY

(One stage assay of factor VIII)

PROCEDURE:

Place the kaolin, phospholipid and $\mathrm{cacl}_{2}$ at $37^{\circ} \mathrm{C}$ and the patient's standard and substrate plasma in the ice bath. Make a lin 10 dilution of the test and standard plasma in buffered saline in plastic tubes in the ice bath. Using $0.2 \mathrm{mls}$ volumes make doubling dilutions in buffered saline to obtain 1 in 20 and 1 in 40 dilutions. Place $0.1 \mathrm{ml}$ of the three dilutions ( 1 in 10, 1 in 20 and 1 in 40) in glass tubes. 
Add to each dilution $0.1 \mathrm{ml}$ of freshly reconstituted substrate plasma and warm at $37^{0} \mathrm{C}$. Add $0.2 \mathrm{ml}$ of the phosspholipid/kaolin mixture. Mix the contents of the tube and start a stop watch. At 10mins, add $\mathrm{cacl}_{2}$ and start a second stop watch. Record the clotting time.

Plot the clotting time of the test and the standard against the concentration of factor viii. The normal range is 50 $200 \mathrm{IU} / \mathrm{L}$.

\section{STATISTICAL ANALYSIS}

The data obtained were subjected to some statistical analysis such as the mean (X), standard deviation (SD), standard error of mean (SEM), student's t-test and Pearson moment of correlation using statistical package for social sciences (SPSS) version 17. The results were expressed in mean \pm standard error of mean

\section{Results}

The mean value of CD4 Count among the study subjects are shown in table 1. CD4 counts were significantly lower in HIV patients $(\mathrm{P}<0.05)$ when compared with the seronegative subjects (control).

Table 1: The Mean Values Of Cd4 Count Among The Study Group

NB: Figures are in mean \pm standard deviation; $n=$ number tested.

\begin{tabular}{|l|l|l|l|}
\hline Parameter & $\begin{array}{l}\text { HIV Negative subjects } \\
(\mathbf{n}=\mathbf{5 0})\end{array}$ & $\begin{array}{l}\text { HIV Positive subjects } \\
(\mathbf{n}=\mathbf{1 1 4})\end{array}$ & P Value \\
\hline $\mathrm{CD} 4(\mathrm{cells} / \mu \mathrm{l})$ & $940 \pm 220.05$ & $360.0 \pm 107.09$ & $\mathrm{P}<0.05$ \\
\hline
\end{tabular}

The mean value of platelet Count among the study subjects are shown in table 2. platelet counts were significantly lower in HIV patients $(\mathrm{P}<0.05)$ when compared with the seronegative subjects (control).

Table 2: The Mean Values Of Platelet Count Among The Study Group

\begin{tabular}{|l|l|l|l|}
\hline Parameter & $\begin{array}{l}\text { HIV Negative subjects } \\
(\mathrm{n}=\mathbf{5 0})\end{array}$ & $\begin{array}{l}\text { HIV Positive subjects } \\
(\mathrm{n}=\mathbf{1 1 4})\end{array}$ & P Value \\
\hline Platelet $\left(\times 10^{9}\right)$ & $\mathbf{2 2 8 . 0 0} \pm \mathbf{6 2 . 0 4}$ & $\mathbf{1 5 7} \pm \mathbf{9 8 . 4 0}$ & $\mathbf{P}<\mathbf{0 . 0 5}$ \\
\hline
\end{tabular}

NB: Figures are in mean \pm standard deviation; $n=$ number tested.

The mean value of prothrombin time among the study subjects are shown in table 3 . Prothrombin time were significantly lower in HIV seronegative subjects (control). $(\mathrm{P}<0.05)$ when compared with the HIV positive subjects.

Table 3: The Mean Values Of Prothrombin Time Among The Study Group

\begin{tabular}{|l|l|l|l|}
\hline Parameter & $\begin{array}{l}\text { HIV Negative subjects } \\
(\mathbf{n}=\mathbf{5 0})\end{array}$ & $\begin{array}{l}\text { HIV Positive subjects } \\
(\mathbf{n}=\mathbf{1 1 4})\end{array}$ & $\mathbf{P}$ Value \\
\hline Prothrombin Time(s) & $\mathbf{1 4 . 9 0} \pm \mathbf{1 . 9 1}$ & $\mathbf{1 9 . 5 6} \pm \mathbf{3 . 1 4}$ & $\mathbf{P}<\mathbf{0 . 0 5}$ \\
\hline
\end{tabular}

NB: Figures are in mean \pm standard deviation; $n=$ number tested.

The mean value of APTT among the study subjects are shown in table 4. APTT were significantly lower in HIV seronegative subjects (control) $(\mathrm{P}<0.05)$ when compared with the HIV positive subjects.

Table 4: The Mean Values Of Aptt Among The Study Group

\begin{tabular}{|l|l|l|l|}
\hline Parameter & $\begin{array}{l}\text { HIV Negative subjects } \\
(\mathbf{n}=\mathbf{5 0})\end{array}$ & $\begin{array}{l}\text { HIV Positive subjects } \\
(\mathbf{n}=\mathbf{1 1 4})\end{array}$ & P Value \\
\hline APTT (s) & $\mathbf{3 7 . 9 0} \pm \mathbf{3 . 9 8}$ & $\mathbf{4 2 . 8 6} \pm 7.10$ & $\mathbf{P}<\mathbf{0 . 0 5}$ \\
\hline
\end{tabular}

NB: Figures are in mean \pm standard deviation; $n=$ number tested.

The mean value of Fibrinogen among the study subjects are shown in table 5. Fibrinogen concentration showed no significant difference among HIV positive subjects $(\mathrm{p}>0.05)$ when compared to the HIV negative subjects (control).

Table 5: The Mean Values Of Fibrinogen Among The Study Group

\begin{tabular}{|l|l|l|l|}
\hline Parameter & $\begin{array}{l}\text { HIV Negative subjects } \\
(\mathbf{n}=\mathbf{5 0})\end{array}$ & $\begin{array}{l}\text { HIV Positive subjects } \\
(\mathbf{n}=\mathbf{1 1 4})\end{array}$ & P Value \\
\hline Fibrinogen (mg/dl) & $\mathbf{2 1 9 . 0 0 \pm 6 3 . 4 6}$ & $\mathbf{2 5 3 . 0 0} \pm \mathbf{1 5 2 . 2 0}$ & $\mathbf{P}>\mathbf{0 . 0 5}$ \\
\hline
\end{tabular}

NB: Figures are in mean \pm standard deviation; $n=$ number tested.

The mean value of Factor Viii among the study subjects are shown in table 6. Factor Viii concentration showed no significant difference among HIV positive subjects $(p>0.05)$ when compared to the HIV negative subjects (control). 
Table 6: The Mean Values Of Factor Viii Among The Study Group

\begin{tabular}{|l|l|l|l|}
\hline Parameter & $\begin{array}{l}\text { HIV Negative subjects } \\
(\mathrm{n}=\mathbf{5 0})\end{array}$ & $\begin{array}{l}\text { HIV Positive subjects } \\
(\mathrm{n}=\mathbf{1 1 4})\end{array}$ & P Value \\
\hline Factor viii $\boldsymbol{\mu} / \mathbf{l}$ & $\mathbf{7 1 . 9 4} \pm \mathbf{1 2 . 6 0}$ & $\mathbf{7 0 . 0 0} \pm \mathbf{1 3 . 2 9}$ & $\mathbf{P}>\mathbf{0 . 0 5}$ \\
\hline
\end{tabular}

NB: Figures are in mean \pm standard deviation; $n=$ number tested.

With a CD4 count of 200 cells / $\mu$ l as baseline, the platelet counts of HIV patients with CD4 $<200$ cells $/ \mu 1$ were lower, but did not differ significantly $(\mathrm{P}>0.05)$ from those with CD4 count $\geq 200$ cells $/ \mu 1$. However, PT and APTT were significantly higher $(\mathrm{P}<0.05)$ respectively in HIV positive subjects with CD4 count $<200$ cells/ $\mu$ l. whereas, fibrinogen and factor viii concentration showed no significant difference (P $>0.05$ )

This result is summarized in Table 7 .

Table 7: The Effect Of Cd4 Counts On Coagulation Parameters Among The Study Groups

\begin{tabular}{|l|l|l|l|}
\hline Parameter & $\begin{array}{l}\text { HIV Patients with CD4 } \\
\text { count }<\mathbf{2 0 0} \text { cells/ } \boldsymbol{\mu l} \\
(\mathbf{n}=\mathbf{4 0})\end{array}$ & $\begin{array}{l}\text { HIV Patients with CD4 count } \geq \\
\mathbf{2 0 0} \text { cells/ } \boldsymbol{\mu l} \\
(\mathbf{n}=\mathbf{7 4})\end{array}$ & P Value \\
\hline Platelet count $\left(\times 10^{9}\right)$ & $140.41 \pm 64.20$ & $169.31 \pm 68.52$ & $\mathrm{P}>0.05$ \\
\hline Prothrombin time $(\mathrm{s})$ & $22.40 \pm 2.96$ & $18.66 . \pm 3.41$ & $\mathrm{P}<0.005$ \\
\hline APTT $(\mathrm{s})$ & $48.20 \pm 8.01$ & $40.34 \pm 5.20$ & $\mathrm{P}<0.001$ \\
\hline Fibrinogen $(\mathrm{mg} / \mathrm{dl})$ & $254.00 \pm 58.01$ & $247.00 \pm 60.00$ & $\mathrm{P}>0.001$ \\
\hline Factor viii $(\mu / \mathrm{l})$ & $73.00 \pm 12.66$ & $75 \pm 14.10$ & $\mathrm{P} 0.001$ \\
\hline
\end{tabular}

NB: Figures are in mean \pm standard deviation; $n=$ number tested.

The correlation of values of CD4 count, PT, APTT, Platelet, Fibrinogen factor viii among HIV patients is as shown in table 4.3 below.

There were positive correlations between PT and APTT, PT and CD4 count, APTT and CD4 count, platelet and $\mathrm{CD} 4$ count $(\mathrm{P}<0.01)$ respectively, while there were no correlation between other parameters $(\mathrm{P}>0.01)$.

Table 8 Correlations Of Values Of Pt, Aptt, Fibrinogen, Platelet, Cd4 Count And Factor Viii Among Hiv Patients.

\begin{tabular}{|c|c|c|c|c|c|c|c|}
\hline & APTT & Fibrinogen & Platelet & CD4 count & Factor viii & $\mathrm{PT}$ & $\mathrm{N}=114$ \\
\hline PT & $\begin{array}{l}\mathrm{r}=0.001 \\
\mathrm{p}<0.01\end{array}$ & $\mathrm{r}=0.175 \quad \mathrm{p}>0.01$ & $\begin{array}{l}\mathrm{r}=0.614 \\
\mathrm{p}=0.01\end{array}$ & $\begin{array}{l}\mathrm{r}=0.003 \\
\mathrm{p}<0.01\end{array}$ & $\begin{array}{l}r=0.965 \\
p>0.01\end{array}$ & 1 & \\
\hline APTT & 1 & $\begin{array}{ll}r>0.329 & p> \\
0.01 & \end{array}$ & $\begin{array}{l}\mathrm{r}=0.002 \\
\mathrm{p}>0.01\end{array}$ & $\begin{array}{l}\mathrm{r}=0.002 \\
\mathrm{p}<0.01\end{array}$ & $\begin{array}{l}\mathrm{r}=0.449 \\
\mathrm{p}>0.01\end{array}$ & $\begin{array}{l}\mathrm{r}=0.001 \\
\mathrm{p}<0.01\end{array}$ & \\
\hline Fibrinogen & $\begin{array}{l}r=0.329 \\
p>0.01\end{array}$ & 1 & $\begin{array}{l}\mathrm{r}=0.237 \\
\mathrm{p}>0.01\end{array}$ & $\begin{array}{l}r=0.504 \\
p>0.01\end{array}$ & $\begin{array}{l}r=0.857 \\
p>0.01\end{array}$ & $\begin{array}{l}r=0.175 \\
p>0.01\end{array}$ & \\
\hline Platelet & $\begin{array}{l}r=0.334 \\
p>0.01\end{array}$ & $\mathrm{r}=0.237$ & $\mathrm{r}=1$ & $\begin{array}{l}\mathrm{r}=000 \\
\mathrm{p}<0.01\end{array}$ & $\begin{array}{l}r=0.857 \\
p>0.01\end{array}$ & $\begin{array}{l}r=614 \\
p>0.01\end{array}$ & \\
\hline CD4 count & $\begin{array}{l}\mathrm{r}=0.02 \\
\mathrm{p}<0.01\end{array}$ & $\begin{array}{l}\mathrm{r}=0.504 \\
\mathrm{p}>=00.1\end{array}$ & $\begin{array}{l}\mathrm{r}=000 \\
\mathrm{p}<0.01\end{array}$ & $\mathrm{r}=1$ & $\begin{array}{l}\mathrm{r}=0.249 \\
\mathrm{p}>0.01\end{array}$ & $\begin{array}{l}\mathrm{R}=0.003 \\
\mathrm{P}<0.01\end{array}$ & \\
\hline Factor viii & $\begin{array}{l}\mathrm{r}=0.449 \\
\mathrm{p}>0.01\end{array}$ & $\mathrm{r}=0.296$ & $\begin{array}{l}\mathrm{r}=0.857 \\
\mathrm{p}>0.01\end{array}$ & $\begin{array}{l}\mathrm{r}=0.249 \\
\mathrm{P}>0.01\end{array}$ & $\mathrm{r}=1$ & $\begin{array}{l}r=0.965 \\
p>0.01\end{array}$ & \\
\hline
\end{tabular}

\section{Discussion}

HIV infection is associated with endothelial dysfunction and liver damage. Both endothelial dysfunction and liver damage can result in coagulation defects. It is therefore expected that as the HIV infection progresses, the coagulation abnormalities will increase, (Linder et al., 1970)

Result obtained in this study showed a significant reduction in CD4 count in HIV patients when compared to their seronegative control ( $p<0.05$ ), which conforms to the work of Omoerge et al.(2009), who found a significant reduction in CD4 count of HIV positive individuals when compared with the seronegative controls. The HIV attacks and destroys cells with the CD4 antigen and this explains why HIV positive patients had lower CD4 counts than HIV - Negative individuals (control) (Lafeuiliade et al., 1992).

Similar to CD4 count, the platelet count was significantly lower in HIV seropositive patients $(\mathrm{p}<0.05)$ when compared to the seronegative controls which also agree with the works of Omorege et al.(2009) and van Gorp et al(, 1999), who independently established a significant reduction in platelet count among HIV positive patients in their separate studies. Impaired thrombopoiesis and production of anti platelet antibodies have been suggested as possible mechanisms (Karpatkin et al., 2002). Impaired thrombopoiesis can result from infection of megakaryocytes by HIV, because megakaryocytes posses CD4 and CXCR4, which are known receptors for HIV, and various megakaryocytes lines are infectable with HIV, (Najen \& Rain 1994).

The PT and APTT in HIV patients were significantly higher than the values obtained in HIV Negative controls $(\mathrm{P}<0.05)$ which also agrees with the works of Omorege et al., 2009, who reported a significant 
increase PT and APTT among HIV positive patients. HIV infection is associated with endothelial damage, which can result in activation of coagulation pathways and consumption of clotting factors (Jenkins et al., 1991). Also, Lupus anticoagulant (LA), anticardiolopin antibodies (CL) and Liver damage are seen in HIV infected patients. All these (Damaged endothelium, LA. aCL and Liver damage) can affect PT and APTT Values observed among HIV patients (Ehmam et al., 1997).

The fibrinogen concentration and factor viii concentration in HIV patients showed no significant difference when compared to the HIV seronegative controls $(p>0.05)$. This could be because, some of the HIV positive subjects were on anti retroviral drugs or as a result of the method employed.

The CD4 count is used as a measure of immune status and disease progression, and values $<200$ cells $/ \mu 1$ make the patients vulnerable to opportunistic infections and other AIDS- defining conditions. Thus, on the basis of CD4 count, the studied coagulation parameters may also indicate disease progression. However, the result obtained in this study, showed no significant difference $(p>0.05)$ in the platelet count of HIV-positive patients whose CD4 Count were $<200$ cells $/ \mu$ land those with CD4 count $\geq 200$ cells $/ \mu 1$, which also agrees with the works of Omorege et al( 2009).

It has been reported that patients with AIDS have decreased platelet production whereas patients with early onset HIV infection are more likely to have increased peripheral destruction of platelet by anti platelet antibodies. Both Mechanisms result in low platelet count in HIV-positive patients with CD4 Count $<200$ cells $/ \mu 1$ and those with $\geq 200$ cells $/ \mu$ and may explain the findings in this study. The PT $(\mathrm{P}<0.05)$ and APTT $(\mathrm{p}<0.05)$ of HIV -positive patients with CD4 count $<200$ cells/ $\mu \mathrm{l}$ were significantly higher than those of HIV patients with CD4 Count $\geq 200$ cells/ $\mu$ l. The possible explanation is that as the HIV infection progressed, which is characterized by reduction in CD4 count, endothelia activation and possibly liver damage may increase, resulting in consumption of blood clotting factors or abnormal production of liver dependent clotting factors, resulting in increased PT and APTT (van Gorp et al., 1999).

The correlation between CD4 count, platelet count, PT, APTT, Fibrinogen and factor viii showed that there were positive correlation between PT and APTT, PT and CD Count, APTT and CD4 count, Platelet and $\mathrm{CD} 4$ count, $(\mathrm{P}<0.01)$ respectively, while there were no correlation between other parameters tested, $(\mathrm{P}>0.01)$. From this study it seems likely that PT and APTT could be used as a means of HIV disease progression in resources-poor setting where CD4 count is impossible.

\section{Conclusion}

Coagulation abnormalities have been described in HIV disease. HIV infection has been associated with endothelial dysfunction which may result in activation and consumption of coagulation factors and ultimately coagulation defect.

The findings of this study indicates an increase in PT and APTT in HIV Positive individuals with a decrease in CD4 and platelet count whereas fibrinogen and factor VIII concentrations showed no significant changes .However, there were positive correlations between CD4 count and platelet, CD4 Count and PT, CD4 count and APTT, and PT and APTT, while no correlation was observed with fibrinogen and factor viii concentrate

\section{References}

[1]. Acharga, S., Dimichele, D., M., (2008)."Rare inherited disorders of fibrinogen”. Haemophilia: the Official Journal of the World Federation of Haemophilia; 14 (6):1151-1158.

[2]. Ascher, M., S., Sheppard, H., W., (1990). AIDS as immune system activation. J. Acquired Immune Deficiency Syndromes; $3: 177$.

[3]. Baker, F., J, Silverton, R., E., Pallister, C., J., (2007). Haemaostasis in Introduction to Medical Laboratory Technology. $7^{\text {th }}$ ed, Honeyland Resources limited. PP 387.

[4]. Centres for Disease Control and Prevention (2009). Guidelines for prevention and treastment of opportunistic infections in HIV-1 infected adults and adolescents: Recommendations from CDC, the national institutes of Health and the HIV medicine association of the infectious diseases society of America.

[5]. Clauss A, (1957). Rapid physiological coagulation method in determination of fibrinogen. Acta haematologia. 17: 237-246.

[6]. Cohan AJ, Philips TM, K essler CM, (1986). Circulating coagulation inhibitors And AIDs. Ann. Intern. Med, 104: 175180

[7]. Ehmann, W., C., Rabkins, C., S., Eyster, M., E., Goedert, J., J., (1997). Thrombocytopenia in HIV-infected and uninfected haemophiliacs. Am J Hematol ; 54:296-300.

[8]. Fox, C., H., Cottler-Fox, M., (1992). The pathology of HIV infection. Immunol. Today; 13: 353.

[9]. Greene, W., C., (1991). The molecular biology of human immunodeficiency virus type 1 infection. New Engl. J. Med; 324: 308.

[10]. Horsti, J., Uppa, H., Vilpo, J., A., (2005). " Poor agreement among prothrombin time international normalized ratio method". Clinical Chemistry; 51(3): 553-560.

[11]. Jenkins, R., E., Peters, B., S., Pinchi, A., J., (1991). Thromboembolic disease in AIDS is associated with cytomegalovirus. AIDS ; 5:1540-1542.

[12]. Karpatkin, S., Nardi, M., Green, D., (2002). Platelet and coagulation defects associated with HIV-1 infection. Thromb Haemost; 88 : 389-401.

[13]. Kuby, J., (1997). The immune system in AIDS. In Immunology: $3^{\text {rd }}$ edition; Freeman and Company. Pp 523-541.

[14]. Linder, M., Muller-Berghaus, G., Lasch, H., G., (1970). Virus infection and blood coagulation. Thromb Diath Haemorrh; 120:129152. 
[15]. Llorente, M., R., Carton, J., A., Carcaba, V., (1994). Antiphospholipid antibodies in human immunodeficiency virus infection. Med Clin (Barc); 103: 10-13.

[16]. Najean Y, Rain JD. (1994). The mechanism of thrombocytopenia in patients With HIV infection. J Lab Clin Med. 123: 415-420.

[17]. Omoregie, R., Osakwe, S., I., Ihemeje, V., Omokaro, E., U., Ogefere, H., O., (2009). Correlation of CD4 count with platelet count, prothrombin time, activated partial thromboplastin time among HIV patients in Benin City, Nigeria. West Indian Med. J; 58(5): 1-9.

[18]. Pagana, K., D., Pagana, T.J.(2006). Mosby's Manual Of Diagnostic and Laboratory tests. $3^{\text {rd }}$ edition St. Louis: Mosby. Pp230-233.

[19]. Pantaleo, G., Fauci, M., S., (1995). New concepts in the immunopathogenesis of HIV infection. Annu. Rev. Immunol.; 13: 487.

[20]. Quick, A., J., Stanley-Brown, M., Bancroft, F., (1935). "A study of the coagulation defect in haemophilia and in jaundice". American Journal of Medical Sciences; 190: 501-502.

[21]. Safrit, J., T., Koup, R., A., (1995). The immunology of primary HIV infection: which immune responses control HIV replication? Curr. Opin. Immunol.; 7: 456.

[22]. Shapiro, S., S., (2003). "Treating thrombosis in the $21^{\text {st }}$ century" New English Journal of Medicne; 349(18): 1762-1764.

[23]. Tolstrup, M., Ostergaard, L., Laursen, A., L., (2004). "HIV/SIV escape from immune surveillance: focus on Nef”. Curr. HIV Res; 2(2):141-151.

[24]. Van Gorp, E., C., M.,Suharti, C., ten Cate, H., Dolmans, W., M., V., van deer Meer, J., W., M., ten Cate, J., W., Brangjes, D., P., M., (1999). Review: Infectious Diseases and coagulation Disorders. The Journal of Infectious diseases; 180:176-186.

[25]. Weiss, R., A., (1993). How does HIV cause AIDS. Nature; 460(7256): 711-716. 